У статті розглянуто алгоритм агрегування простору ознак будівельного комплексу. Він заснований на застосуванні двох критеріїв: коефіцієнта кореляції та критерію несуперечності. Це дозволяє змениити розмірність простору ознак будівельного комплексу. На підставі запропонованого алгоритму можливо підвищити точність кластеризацї областей України за параметрами, що характеризує функціонування будівельного сектора територіі

Ключові слова: будівельна галузь, будівельний комплекс, ознаковий простір, критерій несуперечності, коефічієнт корелячї

В статье рассмотрен алгоритм агрегирования признакового пространства строительного комплекса. Он основан на применении двух критериев: коэффициента корреляции и критерия непротиворечивости. Это позволяет уменьиить размерность признакового пространства строительного комплекса. На основании предложенного алгоритма возможно повысить точность кластеризации областей Украины по параметрам, характеризующим функционирование строительного сектора территории

Ключевые слова: строчтельная отрасль, строительный комплекс, признаковое пространство, критерий непротиворечивости, коэффициент корреляции
УДК 519.237.8:65.02.123:69

ПОСТРОЕНИЕ АГРЕГАТОВ ПРИЗНАКОВ СТРОИТЕЛЬНОГО КОМПЛЕКСА ТЕРРИТОРИИ ДЛЯ КОНЦЕПТУАЛЬНОЙ \section{СХЕМЫ ГРУППИРОВКИ}

\author{
О. М. З З лунина \\ Кандидат технических наук, доцент \\ Кафедра менеджмента \\ Кременчугский национальный университет \\ им. М. Остроградского \\ ул. Первомайская, 20, г. Кременчуг, \\ Полтавская обл., Украина, 39600 \\ E-mail: olvialavina@yandex.ru
}

\section{1. Введение}

Строительство является индикатором развития государства. Существенное влияние на общее состояние строительной отрасли оказывает фактор замедления деловой активности. Развитие строительной отрасли Украины в целом неразрывно связано с деятельностью строительного сектора каждого из регионов. На современном этапе в стране наблюдается неэффективная региональная политика и низкий уровень строительной деятельности, что является следствием отсутствия определенного системного подхода к осуществлению строительной политики. Среди других причин такого положения можно считать недостаточную поддержку со стороны государства, несостоятельность строительных организаций быстро приспособиться к резким изменениям в экономике страны, высокие расходы на возможные нововведения, которые очень трудно окупить. Для каждого региона Украины является актуальным решение задачи по выбору индивидуального направления развития строительной деятельности, учитывая все возможные препятствия. Существует потребность в разработке стратегического плана дальнейшего развития строительного сектора [1-3]. Построение стратегических планов развития строительства в регионах возможно на основе аналитической систематизации существующих проблем, локализации приоритетных (с точки зрения периода действия) вопросов.
2. Анализ литературных данных и постановка проблемы

В диапазоне многочисленных проблем развитие строительной отрасли Украины занимает важное место. Учитывая роль строительства в жизни общества, ее прямые и обратные связи с экономикой, строительная отрасль должна рассматриваться как часть более сложных экономических и социально-политических систем, подвергнутых разному влиянию факторов внешней среды. При этом, установление стабильного функционирования строительной отрасли, которая определяет темпы развития территории, является основным звеном в ее развитии. Экономические и политические кризисы оказывают воздействие на все сферы экономики, а строительная отрасль выступает своеобразным индикатором глубины кризиса, при этом, чем сильнее кризисные явления в экономике, тем медленнее в последующем строительная отрасль выходит на свой докризисный уровень развития. Связано это с инерцией инвестиционной сферы [4], длительным циклом производства строительной продукции и необходимостью заблаговременного наращивания задела незавершенных объектов для последующего ритмичного ввода их в эксплуатацию [5].

Изучение опубликованных по данным проблемам теоретических концепций [6], методических разработок и практических рекомендаций подтверждает, что ряд методологических вопросов управления формированием и развитием региональной структуры 
строительства еще недостаточно исследованы. Это отрицательно сказывается на эффективности развития строительной отрасли [7].

Насыщенность информационного поля строительной сферы создает предпосылки для разработки методов и алгоритмов структурирования данных.

Необходимость системного анализа для развития территории позволила учесть мировой опыт [8, 9], в создании региональных концепций развития. По аналогии возможно применение подходов в строительном секторе. Решение задач развития строительства, повышение его эффективности требует усиления межотраслевой координации. Группировки данных информационного поля, в данном случае, позволяют существенно облегчить управленческие воздействия не только в строительной отрасли, но и других сферах деятельности, хотя решение задач данного класса неоднозначно [10].

Для выбора и обоснования предложений по повышению эффективности деятельности часто применяют различные методы классификации [11].

Объективная необходимость дальнейшего углубления теоретической и научно - прикладной разработки механизма управления формированием и развитием регионального строительства привела к поиску методов для точной группировки больших баз данных [12].

\section{3. Цель и задачи исследования}

Целью исследования является повышение эффективности стратегических планов развития строительной отрасли путем исследования и разработки алгоритма кластеризации регионов Украины в строительной сфере.

Достижение цели возможно при решении следующей задачи: построить алгоритм агрегирования признаков по критерию непротиворечивости.

\section{4. Алгоритм агрегирования признаков строительного комплекса}

Построение агрегатов признаков выполняют для определения существенных факторов влияния и понижения размерности пространства при кластеризации объектов.

Признаковое пространство - это область варьирования всех признаков совокупности изучаемых явлений. Признаковое пространство строительного комплекса - это целостная совокупность, методов и средств анализа, информационного поля, оценки, прогнозирования, планирования и управления элементами внешней среды строительных предприятий с целью повышения уровня стабильного функционирования [12]. Исходная выборка является избыточно большой. Информационное поле среды строительного сектора, помимо строительной отрасли включает право, общество, заказчиков, поставщиков, банки, проектные и посреднические организации, экономику, рынки труда и капитала, землю.

Говоря о строительной отрасли государства необходимо отметить, что строительный сектор каждой области описывается набором характеристик, кото- рые можно назвать признаками. При этом система учитываемых оценочных показателей не может быть в полной мере использована для региональной дифференциации в рамках Украины, т.к. ряд показателей, формирующих условия системы носят общегосударственный характер и не содержат специфического набора числовых и категориальных данных.

Исходными данными в данной работе, формирующими пространство признаков строительного комплекса каждой области (по отобранным экспертами факторам), являются: $\mathrm{x}_{1}$ - длина ЛЭП по уровням напряжения, $\mathrm{x}_{2}$-площадь территории, $\mathrm{x}_{3}-$ население, $\mathrm{x}_{4}$ - инвестиционные строительные проекты, $\mathrm{x}_{5}-$ строительные объекты, $x_{6}-$ недвижимость, $x_{7}-$ товарный отпуск электроэнергии, $\mathrm{x}_{8}-$ производство строительных материалов, х9 - строительная техника, $x_{10}-$ строительно-монтажные работы на территории.

Для решения задач агрегирования признаков наиболее разработанными являются методы, обоснованные на одновременном построении групп взаимосвязанных признаков (агрегировании признаков) и задании таких факторов (векторов), каждый из которых по тем или иным соображениям максимально связан с признаками одного из агрегатов. То есть, заданное множество признаков $\mathrm{X}=\left(\mathrm{x}_{1}, \ldots, \mathrm{x}_{\mathrm{M}}\right)$ на множество объектов $\mathrm{N}$ необходимо разбить на некоторое множество $\mathrm{G}=\left(\mathrm{G}_{1}, \ldots, \mathrm{G}_{\mathrm{L}}\right)$ и задать множество факторов $\mathrm{F}=\left(\mathrm{f}_{1}, \ldots, \mathrm{f}_{\mathrm{L}}\right)$ таким образом, чтобы функция $\mathrm{I}=\mathrm{F}(\mathrm{G}, \mathrm{F})$ достигла экстремальных значений.

В классических моделях факторного анализа G и $\mathrm{P}$ задаются из соображений наилучшей аппроксимации Х. Так в моделях главных компонент [13] критерием группировки является минимизация суммарной выборочной дисперсии характерных факторов $\frac{1}{\mathrm{~N}} \sum_{\mathrm{I}=1}^{\mathrm{L}} \xi_{\mathrm{i}} \xi_{\mathrm{i}}$, отражающей погрешность представления множества X множеством F; в моделях центроидных компонент - максимизация суммарной связи $\sum_{\mathrm{j}=1}^{\mathrm{M}} \sum_{\mathrm{i}=1}^{\mathrm{L}}\left|\rho\left(\mathrm{x}^{\mathrm{j}} \mathrm{f}^{\mathrm{i}}\right)\right|$ между признаками и факторами. В моделях экстремальной группировки признаков задания факторов производится с помощью экстремализации специально подобранных функционалов, вид которых зависит от способов агрегирования и построения факторов [14].

По мнению Миркина Б. Г. [15], агрегирование признаков и задание факторов необходимо производить в два этапа: на первом - определяются агрегаты признаков и интерпретируют в рамках принятых теоретических представлений; на втором - факторы задаются только в том случае, если произведена соответствующая интерпретация.

Рассматриваемый алгоритм агрегирования признаков основан на применении двух критериев: коэффициента корреляции и критерия непротиворечивости [16]. Алгоритм позволяет получить множество непротиворечивых (истинных) вариантов агрегирования показателей. Выбор того или иного варианта (доопределение агрегирования) производится экспертами в соответствии с задачами исследования. Таким образом, разработанный алгоритм основан на выявлении структуры подобия признаков на представленном 
множестве объектов и не зависит от соображений относительно природы агрегируемых признаков.

Исходные данные представлены матрицей $\mathrm{C}=\left(\mathrm{C}_{\mathrm{i}, \mathrm{j}}\right)$; $\mathrm{i}=\overline{1, \mathrm{~N}} ; \mathrm{j}=\overline{1, \mathrm{M}}$ значений признаков $\mathrm{x}_{1} \ldots \mathrm{x}_{\mathrm{M}}$ на $\mathrm{N}$ объектах (объектами являются области Украины, каждая из которых имеет свои значения признаков). Необходимо разбить имеющиеся признаки таким образом, чтобы агрегаты $\mathrm{G}_{1}^{\mathrm{B}}, \ldots, \mathrm{G}_{\mathrm{L}}^{\mathrm{B}}$, полученные на выборке A, при $\mathrm{A} \cup \mathrm{B}=\mathrm{C}$ и $\mathrm{G}_{\mathrm{i}} \cap \mathrm{G}_{\mathrm{j}}$ при $\mathrm{i} \neq \mathrm{j} ; \mathrm{i}, \mathrm{j}=\overline{1, \mathrm{~L}}$.

Производим нормировку и центрирование исходных данных. После разделения выборки С на А и В. Ранжируем строки матрицы $\hat{\mathrm{c}}=\left(\mathrm{C}_{\mathrm{ij}}\right)$ по значениям величины

$$
\delta_{i}=\frac{1}{M} \sum_{j=1}^{M}\left(c_{i j}\right)^{2}, i=\overline{1, N}
$$

и делим полученную матрицу на части А и В по правилу “чет-нечет".

Построение матриц $\mathrm{R}_{\mathrm{A}}$ и $\mathrm{R}_{\mathrm{B}}$ связи между признаками на выборках А и $\mathrm{B}$.

Производим нормирование и центрирование значений признаков на выборках А и В. Связь между признаками определяется величиной коэффициента корреляции.

После разбиения признаков М-1 агрегата определяем значение критерия непротиворечивости. По матрицам связей между признаками $\mathrm{R}_{\mathrm{A}}$ и $\mathrm{R}_{\mathrm{B}}$ определяется $\max r_{i, j}$ что соответствует объединению в агрегат признаков і и ј. Далее определяем значение коэффициента непротиворечивости:

$$
\mathrm{S}_{\mathrm{M}-1}=(\mathrm{p}-\Delta \mathrm{p}) / \mathrm{p} \text {, }
$$

где р - число образованных на данном шаге вершин агрегатов; $\Delta \mathrm{p}-$ число совпадающих вершин агрегатов на выборках А и В.

Происходит образование L=M-2 агрегатов и т.д. до $\mathrm{L}=2$ агрегата с соответствующим определением значений критерия непротиворечивости

Из полученного набора агрегатов признаков выбираются те, значения непротиворечивости которых равно нулю. Отсутствие нулевых значений коэффициентов может быть вызвано отсутствием агрегатов связанных признаков, высоким уровнем помех в исходных данных при имеющихся существенно нелинейных связях между признаками.

Для каждой области Украины выбраны значения рассматриваемых признаков из источников открытого доступа и статистических данных (площадь территории, население, товарный отпуск электроэнергии, производство строительных материалов, строительная техника и т.д.). Следует считаться с разнородностью информации исследуемой совокупности исходных данных, характеризующих функционирование строительного комплекса региона. Необходимо установление однородности информативных факторов, характеризующих функционирование строительства в областях Украины. Учитывая, что состав совокупности основных признаков гетерогенный, т. е. содержащий разнотипные физические единицы (км, кВт, кол. человек, и т.д.), и все они характеризуют в той или иной мере функционирование строительного комплекса, необходимо преобразование всех значений признаков, т. е. нормировка данных.

Таблица 1

\begin{tabular}{|c|c|c|c|c|c|c|c|c|c|c|c|}
\hline Іри: & & & & & & & & & & & \\
\hline $\begin{array}{l}\text { Номер } \\
\text { области }\end{array}$ & $\mathrm{x}_{1}$ & $\mathrm{x}_{2}$ & $\mathrm{x}_{3}$ & $\mathrm{x}_{4}$ & $x_{5}$ & $\mathrm{x}_{6}$ & $x_{7}$ & $\mathrm{x}_{8}$ & $\mathrm{x}_{9}$ & $\mathrm{x}_{10}$ & $\mathrm{~B}$ \\
\hline 1 & 0.31 & 0.27 & -0.95 & -0.25 & 0.79 & -0.12 & 0.25 & 1.22 & 1.96 & -1.02 & A \\
\hline 2 & 0.38 & -0.05 & -0.01 & -0.30 & -0.42 & -0.36 & 0.37 & -0.66 & 2.06 & -0.98 & B \\
\hline 3 & $-0.61 \mid$ & -0.87 & 1.99 & -0.99 & -0.75 & -0.76 & 0.74 & 0.15 & -1.02 & 0.01 & A \\
\hline 4 & 1.22 & 1.96 & -1.02 & 1.95 & 2.90 & \begin{tabular}{|l|}
3.23 \\
\end{tabular} & 2.21 & -0.54 & 1.59 & 1.13 & B \\
\hline 5 & 0.38 & 3.36 & -1.69 & 3.37 & 2.24 & 3.15 & 2.23 & -1.56 & 1.27 & 1.36 & A \\
\hline 6 & 0.91 & -0.45 & 0.72 & -0.54 & -0.40 & -0.36 & 0.16 & 0.65 & 0.02 & 0.11 & B \\
\hline 7 & -1.77 & -0.66 & 2.06 & -0.98 & -0.85 & -0.57 & 0.15 & -0.01 & -0.29 & -0.13 & A \\
\hline 8 & 0.49 & 0.15 & -1.02 & 0.01 & 0.50 & 0.51 & 0.54 & -0.35 & 0.83 & 0.65 & B \\
\hline 9 & -1.60 & -0.54 & 1.59 & 1.13 & -0.79 & -0.56 & -0.21 & 0.08 & -0.60 & -0.01 & A \\
\hline 10 & 0.63 & -0.03 & -0.48 & 0.24 & -0.30 & -0.25 & -0.12 & 1.44 & 0.66 & -0.48 & B \\
\hline 11 & 0.08 & -0.71 & -0.01 & -0.68 & -0.60 & -0.33 & 0.08 & 0.74 & -0.19 & -0.82 & A \\
\hline 12 & 0.41 & 0.89 & -1.56 & 1.27 & 1.36 & \begin{tabular}{|l|l}
0.72 \\
\end{tabular} & -0.11 & -1.77 & -0.66 & 2.06 & B \\
\hline 13 & -0.35 & 0.83 & 0.65 & 0.02 & 0.11 & -0.25 & -0.83 & 0.49 & 0.15 & -1.02 & A \\
\hline 14 & 0.08 & -0.60 & -0.01 & -0.29 & -0.13 & -0.43 & 0.60 & -1.60 & -0.54 & 1.59 & B \\
\hline 15 & 1.44 & 0.66 & -0.48 & 0.05 & 0.62 & -0.09 & 0.61 & 0.63 & -0.03 & -0.48 & A \\
\hline 16 & 0.74 & -0.19 & -0.82 & 0.43 & -0.31 & -0.20 & -0.02 & 3.37 & 2.24 & 3.15 & B \\
\hline 17 & -0.62 & -0.76 & 2.53 & -0.73 & 0.86 & -0.53 & -0.19 & -0.54 & -0.40 & -0.36 & A \\
\hline 18 & -0.04 & -0.54 & -1.02 & -0.43 & -0.45 & -0.41 & -0.19 & -0.98 & -0.85 & -0.57 & B \\
\hline 19 & -1.61 & -0.77 & 1.05 & -0.87 & -0.85 & -0.50 & -0.01 & 0.01 & 0.50 & 0.51 & A \\
\hline 20 & 1.15 & 1.19 & -1.62 & 0.45 & 1.34 & 0.30 & 2.54 & 1.13 & -0.79 & -0.56 & B \\
\hline 21 & 0.69 & -0.67 & 0.25 & -0.64 & -0.39 & -0.37 & -0.23 & -0.48 & 0.24 & 0.30 & A \\
\hline 22 & -0.54 & -0.43 & 0.18 & -0.50 & -0.69 & -0.41 & -0.41 & -0.01 & -0.68 & -0.60 & B \\
\hline 23 & -0.50 & -0.43 & -0.48 & -0.31 & -0.50 & -0.31 & 1.22 & -1.56 & 1.27 & 1.36 & A \\
\hline 24 & -2.51 & -1.01 & 1.39 & -0.95 & -0.94 & -0.59 & -1.01 & 0.65 & 0.02 & 0.11 & B \\
\hline 25 & 1.22 & -0.58 & -1.22 & $-0.47 \mid$ & -0.57 & -0.44 & -0.58 & -0.01 & -0.29 & -0.13 & A \\
\hline
\end{tabular}

Разделение нормированных и центрированных данных на части А и В

В табл. 1 представлены нормированные и центрированные исходные данные.

Таблица 2

Матрица связи между признаками по части A

\begin{tabular}{|c|c|c|c|c|c|c|c|c|c|c|}
\hline Пр. & $\mathrm{x}_{1}$ & $\mathrm{x}_{2}$ & $\mathrm{x}_{3}$ & $\mathrm{x}_{4}$ & $\mathrm{x}_{5}$ & $\mathrm{x}_{6}$ & $\mathrm{x}_{7}$ & $\mathrm{x}_{8}$ & $\mathrm{x}_{9}$ & $\mathrm{x}_{10}$ \\
\hline $\mathrm{x}_{1}$ & - & 0.71 & 0.4 & 0.3 & 0.85 & 0.5 & 0.9 & 0.85 & 0.4 & 0.5 \\
\hline $\mathrm{x}_{2}$ & - & - & 0.3 & 0.7 & 0.65 & 0.3 & 0.45 & 0.7 & 0.4 & 0.5 \\
\hline $\mathrm{x}_{3}$ & - & - & - & 0.71 & 0.44 & 0.32 & 0.31 & 0.55 & 0.41 & 0.51 \\
\hline $\mathrm{x}_{4}$ & - & - & - & - & 0.11 & 0.45 & 0.15 & 0.21 & 0.42 & 0.54 \\
\hline $\mathrm{x}_{5}$ & - & - & - & - & - & 0.41 & 0.64 & 0.52 & 0.34 & 0.62 \\
\hline $\mathrm{x}_{6}$ & - & - & - & - & - & - & 0.59 & 0.6 & 0.56 & 0.3 \\
\hline $\mathrm{x}_{7}$ & - & - & - & - & - & - & - & 0.2 & 0.21 & 0.21 \\
\hline $\mathrm{x}_{8}$ & - & - & - & - & - & - & - & - & 0.8 & 0.8 \\
\hline $\mathrm{x}_{9}$ & - & - & - & - & - & - & - & - & - & 0.9 \\
\hline $\mathrm{x}_{10}$ & - & - & - & - & - & - & - & - & - & - \\
\hline
\end{tabular}


Результат построения матриц связи $\mathrm{R}_{\mathrm{A}}$ и $\mathrm{R}_{\mathrm{B}}$, по которым определяется степень важности факторов, формирующих классификацию регионов по исследуемым параметрам, приведен в табл. 3.

Таблица 3

Матрица связи между признаками по части В

\begin{tabular}{|c|c|c|c|c|c|c|c|c|c|c|}
\hline$\Pi$ П. & $\mathrm{x}_{1}$ & $\mathrm{x}_{2}$ & $\mathrm{x}_{3}$ & $\mathrm{x}_{4}$ & $\mathrm{x}_{5}$ & $\mathrm{x}_{6}$ & $\mathrm{x}_{7}$ & $\mathrm{x}_{8}$ & $\mathrm{x}_{9}$ & $\mathrm{x}_{10}$ \\
\hline $\mathrm{x}_{1}$ & - & 0.81 & 0.9 & 0.3 & 0.88 & 0.4 & 0.9 & 0.51 & 0.53 & 0.56 \\
\hline $\mathrm{x}_{2}$ & - & - & 0.4 & 0.5 & 0.51 & 0.42 & 0.41 & 0.39 & 0.56 & 0.61 \\
\hline $\mathrm{x}_{3}$ & - & - & - & 0.6 & 0.61 & 0.43 & 0.42 & 0.40 & 0.21 & 0.12 \\
\hline $\mathrm{x}_{4}$ & - & - & - & - & 0.15 & 0.24 & 0.15 & 0.35 & 0.16 & 0.65 \\
\hline $\mathrm{x}_{5}$ & - & - & - & - & - & 0.68 & 0.63 & 0.61 & 0.39 & 0.51 \\
\hline $\mathrm{x}_{6}$ & - & - & - & - & - & - & 0.4 & 0.51 & 0.63 & 0.69 \\
\hline $\mathrm{x}_{7}$ & - & - & - & - & - & - & - & 0.55 & 0.4 & 0.39 \\
\hline $\mathrm{x}_{8}$ & - & - & - & - & - & - & - & - & 0.8 & 0.79 \\
\hline $\mathrm{x}_{9}$ & - & - & - & - & - & - & - & - & - & 0.81 \\
\hline $\mathrm{x}_{10}$ & - & - & - & - & - & - & - & - & - & - \\
\hline
\end{tabular}

В результате разбивки анализируемых показателей на 5 агрегатов получаем следующий результат непротиворечивого агрегирования признакового пространства:

1 агрегат включает - $\left(x_{1} ; x_{2} ; x_{5} ; x_{7} ; x_{8}\right)$

2 агрегат включает - $\left(x_{3}\right)$

3 агрегат включает - $\left(x_{4}\right)$

4 агрегат включает - $\left(x_{9}\right)$

5 агрегат включает - $\left(x_{10}\right)$

\section{5. Выводы}

В работе построен алгоритм агрегирования признаков строительного комплекса регионов по критерию непротиворечивости.

Для построения агрегатов признаков с помощью уже существующих методов необходимо привлечение дополнительной информации посредством принятия предложений о видах функций, либо посредством выбора порога существенности величины рассматриваемых связей между признаками.

Предложенный алгоритм основан на выявлении структуры подобия признаков на представленном множестве объектов и не зависит от соображений относительно природы агрегируемых признаков.

По представленному алгоритму выполнено агрегирование признаков строительного комплекса Украины. В результате проведенного исследования получено пять непротиворечивых (истинных) агрегатов показателей, у которых критерий непротиворечивости равен нулю.

Предположение о возможности повышения точности кластеризации при использовании найденных непротиворечивых агрегатов признаков основано на результатах, в соответствии с которыми точность получаемых результатов увеличивается с понижением размерности пространства признаков. Это позволяет достичь большей вычислительной мощности.

Полученный результат позволяет сделать вывод о наличии непротиворечий взаимосвязи между показателями, формирующими функционирование строительного комплекса региона. Он является промежуточным этапом в построении концептуальной схемы группирования областей, а так же позволяет построить более точную кластеризацию областей для принятия управленческих решений в строительном секторе.

\section{Литература}

1. Каплан, Л. М. Проблемы перестройки экономики строительства при переходе к регулируемому рынку [Текст] / Л. М. Каплан // Экономика строительства. - 1991. - № 2. - С. 65-88.

2. Кулибанов, В. С. Территориальные аспекты управления строительством [Текст ] / В. С. Кулибанов // Экономика строительства. - 1989. - № 1. - С. 12-42.

3. Усов, А. В. Применение модели календарного планирования для проектного управления в строительстве [Текст] / А. В. Усов, С. С. Максимов // Восточно-Европейский журнал передовых технологий. - 2014. - Т. 1, № 4 (67). - С. 39-42.

4. Ярошенко, Ф. О. Державний бюджет і бюджетна стратегія 2012-2014: стабілізація та сталий розвиток в умовах реформування економіки України [Текст] / Ф. О. Ярошенко, Т. І. Єфименко, В. М. Геєць, Е. М. Лібанова та ін.; за заг. ред. М. Я. Азарова. - К. : ДННУ „Акад. фін. управління”, 2011. - 702 с.

5. Сухоруков, А. И. Строительный рынок в мире и Украине [Электронный ресурс] / А. И. Сухоруков, О. П. Морква. - Аналитика компаний. Газета «Бизнес». - Режим доступа: www.business.ua /analutics/1167/. - Название с экрана.

6. Андрухов, В. М. Перспективні напрямки вдосконалення діяльності організацій будівельної галузі України [Текст] / В. М. Андрухов, Л. В. Мартинова // Будівництво України. - 2010. - № 5. - С. 2-6.

7. Громов, О. Дмитро Ісаєнко: Протягом року ми підготуємо довгострокову програму розвитку ринку будівельних матеріалів [Електронний ресурс] / О. Громов. - Урядовий кур’єр. - № 45. - Режим доступу: http://www.ukurier.gov.ua/uk/articles/ dmitro-isayenko-protyagom-roku-mi-pidgotuyemo-dovg/ - 13.03.2012. - Загол. з екрану

8. Помитов, С. А. Мировая экономика. Опыт создания кластерных структур [Електронний ресурс] / С. А. Помитов. - Режим доступа: http:// ekportal.ru/page-id-1910.html. - Название с экрана.

9. Помитов, С. А. Мировая экономика. Кластеры: характеристика и модели [Электронный ресурс] / С. А. Помитов. - Режим доступа: http:// ekportal.ru/page-id-1805.html. - Название с экрана.

10. Estivill-Castro, V. Why so many clustering algorithms - A Position Paper [Text] / V. Estivill-Castro // ACM SIGKDD Explorations Newsletter. - 2002. - Vol. 4 Issue 1. - P. 65-75. doi:10.1145/568574.568575 
11. Székely, G. J. Hierarchical clustering via Joint BetweenWithin Distances: Extending Ward's Minimum Variance Method [Text] / G. J. Székely, M. L. Rizzo // Journal of Classification. - 2005. - Vol. 22, Issue 2. - P. 151-183. doi: 10.1007/s00357-005-0012-9

12. Залунина, О. М. Структурирование ключевых экономических показателей информационного поля строительного сектора Украины [Текст]/ О.М. Залунина // Вісник Кременчуцького національного університету імені Михайла Остроградського. - 2014. - № 1. - С. 52-59.

13. Ивахненко, А. Г. Применение самоорганизации для разбиения множества данных на заранее незаданное число кластеров [Текст] / А. Г. Ивахненко, Ю. В. Коппа, С. А Петрухова, Н. А. Ивахненко // Автоматика и телемеханика. - 1985. - № 5. C. $9-16$.

14. Браверман, Э. М. Структурные методы обработки эмпирических данных [Текст] / Э. М. Браверман, И. Б. Мучник. - М.: Наука, 1983. - $464 \mathrm{c}$.

15. Миркин, Б. Г. Группировки в социально-экономических исследованиях. Методы построения анализа [Текст] / Б. Г. Миркин. - М.: Финансы и статистика, 1985. - 223 с.

16. Ивахненко, А. Г. Объективная компьютерная кластеризация. Теоретические вопросы [Текст] / А. Г. Ивахненко, С. А. Петрухова, Н. А Ивахненко // Автоматика и телемеханика. - 1986. - № 3. - С. 3-11.

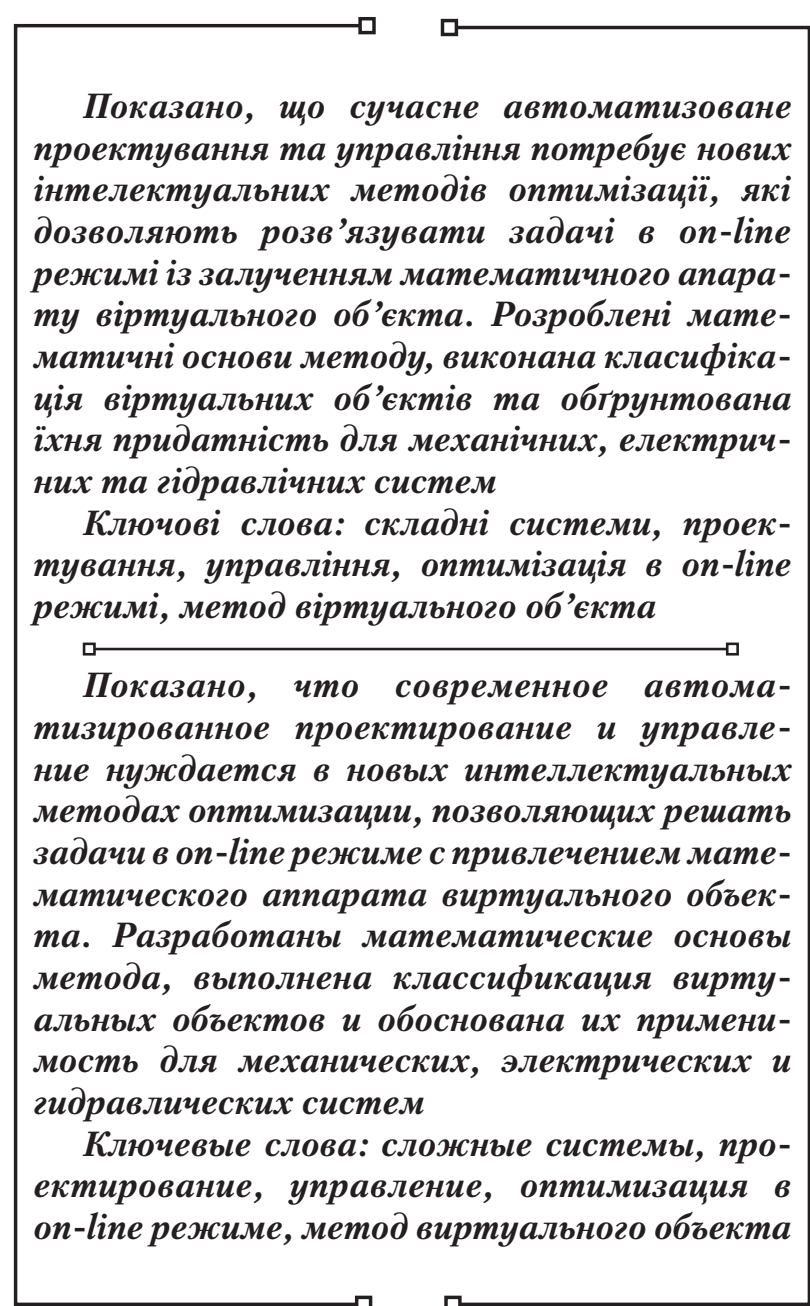

口-
УДК 004.051: 519.876

\section{ОБОБЩЕНИЕ МЕТОДА ВИРТУАЛЬНОГО ОБЪЕКТА НА РАСЧЕТЫ ОПТИМАЛЬНЫХ ПАРАMETPOB СЛОЖНЫХ СИСТЕМ}

\author{
Л. В. Бовнегра \\ Кандидат технических наук, доцент \\ Кафедра компьютерных методов \\ проектирования в машиностроении * \\ E-mail: dlv5@ukr.net \\ Т. В. Л ысенко \\ Доктор технических наук, профессор \\ Кафедра технологии и \\ управления литейными процессами* \\ E-mail: tvl12@list.ru \\ A. А. Станов ский \\ Кафредра компьютерных \\ интеллектуальных систем и сетей* \\ E-mail: redlinenorma@mail.ru \\ пр. Шевченко, 1, г. Одесса, Украина, 65044
}

*Одесский национальный политехнический университет

\section{1. Введение}

Деятельность современных автоматизированных систем проектирования и управления сложными объектами невозможно представить без многократного решения задач оптимизации их параметров, от результатов которых, в основном, и зависит эффективность функционирования таких объектов.

Однако, именно сложность последних заставляет проектировщиков и управленцев не только ускорять расчеты за счет современных средств вычислительной техники, но и искать новые подходы к методам оптимизации, применяемые интеллектуальные математические модели, в частности, методам виртуального объекта.

Современные задачи оптимизации для целей проектирования и управления не могут быть разрешены «в лоб» известными методами в приемлемое время, так как оптимизируемые объекты обладают большой размерностью и «неравномерностью» 